\title{
ВИБРОАКУСТИКА ВВЭР-1200
}

\author{
Аркадов Г.В., Павелко В.И. \\ «Научно - технический центр «ДИАПРОМ», г. Москва \\ Слепов М.Т. \\ Филиал «Концерна Росэнергоатом» Нововоронежская АЭС, г. Нововоронеж
}

В реакторостроении, где торжествуют нейтронная кинетика, теплофизика и гидродинамика, виброакустика стоит как-то в стороне. Вибрация, как один из множества факторов износа оборудования, никакими проектами реакторных установок не считается основным фактором исчерпания ресурса и соответственно, не имеет установленных главным конструктором РУ предельных уровней, как по частотным, так и по амплитудным значениям. Акустика собственно циркуляционных контуров и вовсе не принимается во внимание при обосновании безопасности РУ в любом отечественном или зарубежном проекте. В то же время известны неудачные конструкции реакторных установок, в которых виброакустические эффекты приводили к отказам оборудования или к преждевременному исчерпанию его ресурса. Коварство вибраций состоит в том, что, когда их амплитуда достаточно мала, вкладом вибраций в исчерпание ресурса оборудования можно пренебречь, но они могут играть определяющую роль при резонансных вибрационных явлениях. Резонансное возбуждение вибраций считается недопустимым любым проектом РУ. Не допускаются также ударные акустические воздействия в контурах циркуляции ТН, например, такие, как гидравлические удары. И, тем не менее, они случаются. На блоке 1 НВАЭС-2 с начала пусконаладочных испытаний (ПНИ) посредством стационарных систем диагностирования совместно с переносными измерительными системами проводились многоканальные виброакустические измерения. Итоги этой деятельности подведены в монографии [1], где на экспериментальном материале доказано, что главную роль в формировании вибрационного состояния главного циркуляционного контура (ГЦК) играют акустические стоячие волны (АСB).

\section{Вибрации на собственных частотах и вибрации, вынужденные АСВ}

Три параметра маятника - масса - $M$, демпфирование $-C$ и жёсткость - $K$ - связаны известным уравнением движения (уравнением Лагранжа-Эйлера):

$$
M \cdot \ddot{x}(t)+C \cdot \dot{x}(t)+K \cdot x(t)=f_{0} \cdot e^{j \omega_{1} t}
$$

В качестве вынуждающей гармонической силы $f(t)=f_{0} \cdot e^{j \omega_{1} t}$ могут выступать пульсации давления ТН на единственной частоте $\omega_{1}$, например, на частоте АСВ. Две постоянные времени, как величины, обратные характерным частотам $\Omega_{1}, \Omega_{2}$

$$
\begin{gathered}
\tau_{K}=\frac{1}{\Omega_{2}}=\frac{C}{K}=\frac{\Delta \omega}{\omega_{0}^{2}}=\frac{1}{\omega_{0} \cdot Q}=\frac{2 \alpha}{\omega_{0}} \\
\tau_{M}=\frac{1}{\Omega_{1}}=\frac{M}{C}=\frac{1}{2 \sigma}=\frac{1}{\Delta \omega}=\frac{Q}{\omega_{0}}=\frac{1}{2 \alpha \omega_{0}}
\end{gathered}
$$

выражены через собственные параметры маятника $(M, C, K)$, где $\tau_{M}$ - постоянная времени демпфирования по массе, $\tau_{K}$ - постоянная времени демпфирования по жёсткости, $Q$ добротность резонанса на собственной частоте - $\omega_{0}, \alpha$ - относительный коэффициент демпфирования, $\Delta \omega$ - ширина резонанса. Две постоянные времени $\tau_{M}, \tau_{K}$ связаны с собственной частотой $\omega_{0}$ выражением: 


$$
\tau_{0}=\sqrt{\tau_{K} \cdot \tau_{M}}=\frac{1}{\omega_{0}}=\sqrt{\frac{M}{K}},
$$

Экспериментальное оценивание постоянных времени $\tau_{K}, \tau_{M}$ даёт диагностические параметры вибраций на собственной частоте. Фазочастотная характеристика «сила - перемещение» между возмущением со стороны АCВ (пульсациями давления ТН) и ответной реакцией в виде виброперемещений - $x(t)$ с частотами вынуждающих сил $-f_{1}$ и собственной частотой колебаний $-f_{0}$ линеаризуется:

$$
\operatorname{tg} \varphi(F)=\frac{2 \alpha F}{1-F^{2}} \approx\left\{\begin{array}{c}
2 \alpha F=2 \pi f \tau_{K}, \quad \text { где } F=\frac{\omega}{\omega_{0}}, \quad \omega \sim 0, \\
\mp \frac{\pi}{2}, \quad F=1 \text { или } \omega=\omega_{0} \\
\frac{C}{M \omega}=\frac{1}{2 \pi f \tau_{M}}, \quad \alpha \ll 1, \quad \omega \gg \omega_{0}
\end{array},\right.
$$

в результате чего диагностическим признаком является простое время запаздывания между пульсациями давления и виброперемещением (рис. 1):
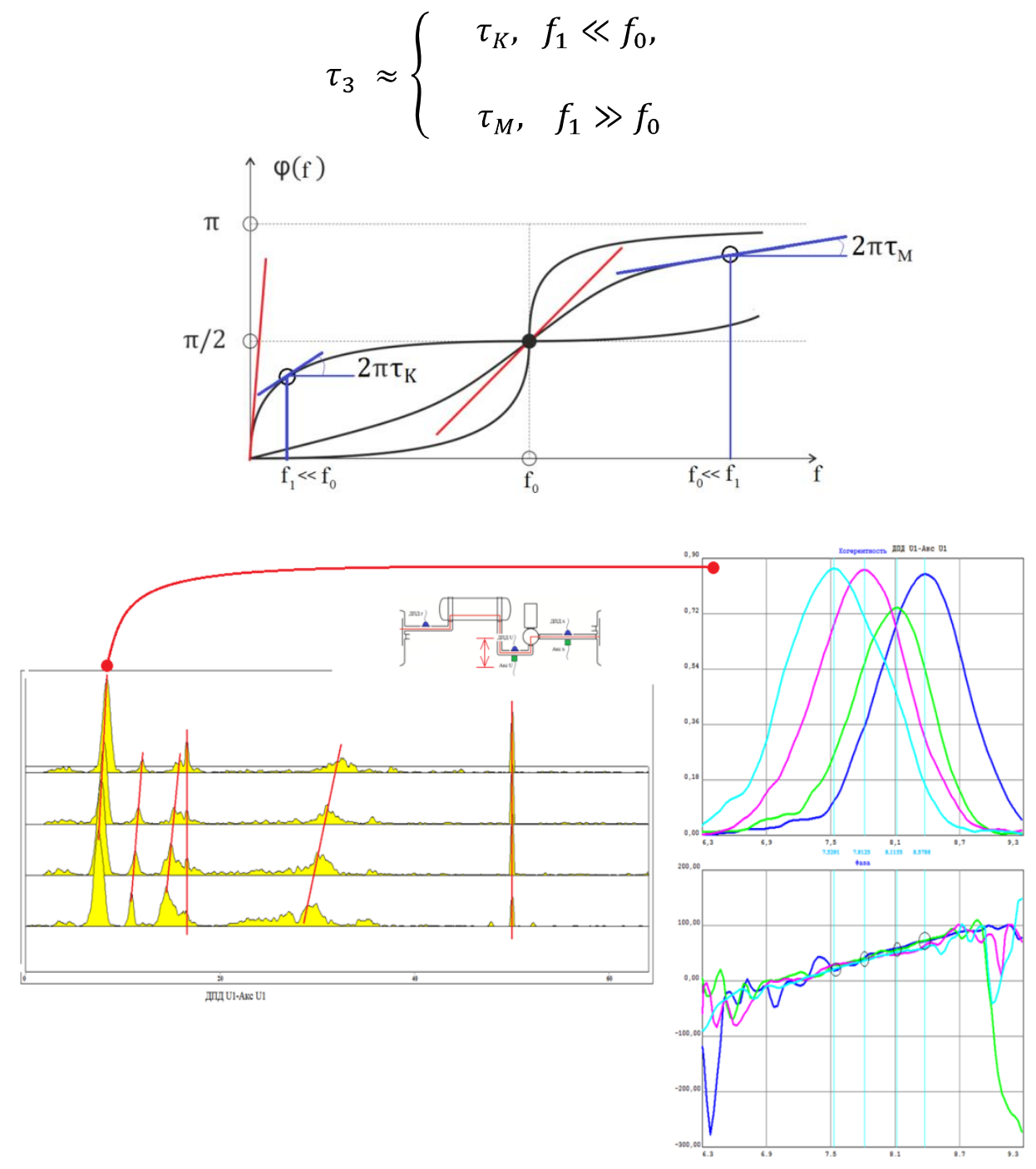

Рис. 1. Фазочастотная характеристика (верхний график) и семейства функций когерентностей и фаз при разогреве блока по сигналам ДПДU-AксU 
Время запаздывания и наклон фазовый характеристики, являются функциями двух параметров системы $(M, C$ или $K, C)$, то есть являются диагностическими признаками, характеризующими, в частности, рассеиваемую системой мощность. Частоты стоячих волн

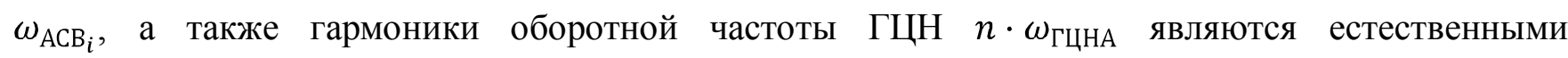
дискретными реперами, которые задают дискретные по частоте силы, всегда присутствующие в ГЦК.

Тройка вибрационных параметров $(M, C, K)$ может незначительно изменяться в процессе эксплуатации РУ, например, из-за естественных флуктуаций режимных параметров РУ (температуры ТН, давления, расхода и т.д.), а может, из-за какой-либо аномалии. Тройка параметров $(M, C, K)$ связана с тройкой параметров $\left(\omega_{0}, H\left(\omega_{0}\right), Q\right)$, характеризующих вибрационный резонанс выражениями: $\omega_{0} \approx \sqrt{\frac{K}{M}}, H\left(\omega_{0}\right) \approx \frac{\sqrt{M}}{C \sqrt{K}}, Q \approx \frac{\sqrt{K M}}{C}, \quad$ где $H\left(\omega_{0}\right)-$ амплитуда резонанса. Отсюда следуют их взаимные свойства (таблица 1):

Таблица 1. Корреляция пар функций времени при изменении параметр.

\begin{tabular}{|c|c|c|c|}
\hline $\begin{array}{c}\text { Изменяемый параметр ДС } \\
\text { Пара функций времени }\end{array}$ & $M$-масса & $C$-демпфирование & $K$-жёсткость \\
\hline$\omega_{0}(\boldsymbol{t}), \boldsymbol{Q}(\boldsymbol{t})$ & противофазные & синфазные & синфазные \\
\hline$\omega_{0}(\boldsymbol{t}), \boldsymbol{H}(\boldsymbol{t})$ & противофазные & синфазные & противофазные \\
\hline $\boldsymbol{H}(\boldsymbol{t}), \boldsymbol{Q}(\boldsymbol{t})$ & синфазные & синфазные & противофазные \\
\hline
\end{tabular}

Длительные измерения параметров резонанса, например, в течение всей кампании, с последующим коррелированием между собой функций времени $\omega_{0}(t), H(t), Q(t)$, дают информацию о причине происхождения аномалии: то ли меняется масса, то ли демпфирование, то ли жёсткость вибрационной системы. На рис. 2 представлены кривые, в результате 230-ти измерений. Функции времени $\omega(t)$ и $Q(t)$ демонстрируют противофазное поведение, их ВКФ демонстрирует сильную антикорреляцию. Это свойственно именно вибрационному резонансу на собственной частоте.
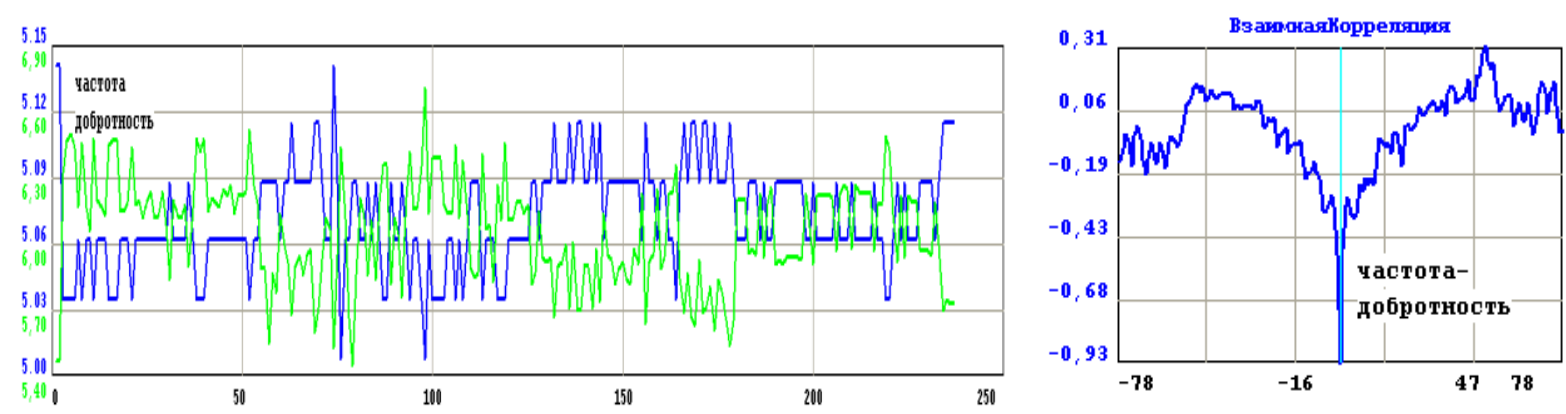

Рис. 2. Оценки частоты и добротности резонанса собственных колебаний ПГ, как функции времени и их ВКФ (справа).

Коррелировать можно не только параметры одного резонанса, но и любую пару параметров резонансов, расположенных на разных частотах. Например, амплитуды двух резонансов. Значимо большие положительные корреляции или синфазности означают, что эти два резонанса имеют один общий источник или находятся в генетическом родстве.

В процессе разогрева РУ частоты АСВ монотонно уменьшаются, и неминуемо происходит их совпадение с гармониками оборотной частоты ГЦНА. Таких точек на рис. 3 оказалось довольно много - 7 штук. Такие совпадения частот называют резонансными возбуждениями, и они происходят всякий раз при разогреве/расхолаживании блока в диапазоне рабочих температур ТН без каких-либо заметных изменений амплитуд вибраций. Таким образом, штатные динамические режимы являются своего рода естественными тестами, подтверждающими 
достаточность демпфирования конструкции РУ. В этих же измерениях получена температурная зависимость скорости звука в акустическом тракте ВВЭР-1200: $C(T)=1420-2,07 \cdot T$.
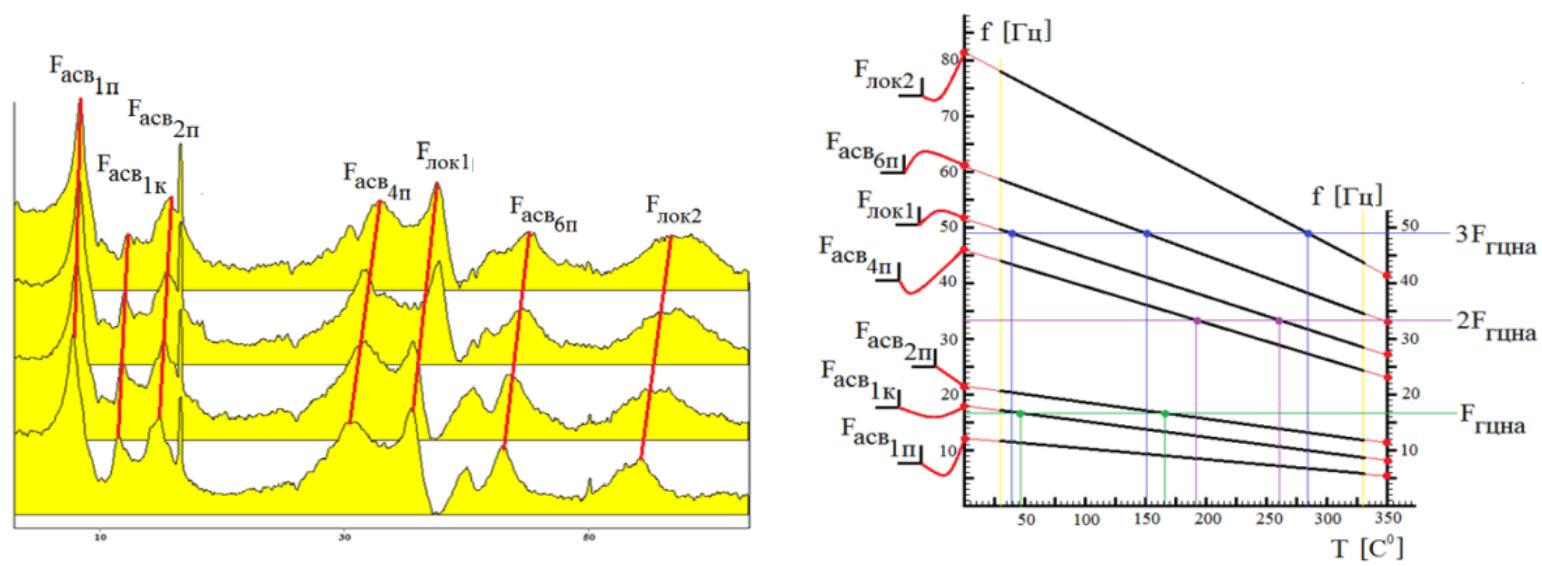

Рис. 3. Семейство АСПМ сигналов датчика ДПДг1 при монотонном увеличении температуры ТН от $120^{\circ}$ до $280^{\circ}$ и частоты АСВ (справа)

Длительные и непрерывные измерения вибраций совместно со штатными сигналами АСУ ТП дают ключ к пониманию источников вибраций. Так, в течение разогрева блока непрерывно фиксировались сигналы акселерометров, установленных на корпусе РУ и перепады давления на ГЦНА (рис. 4).

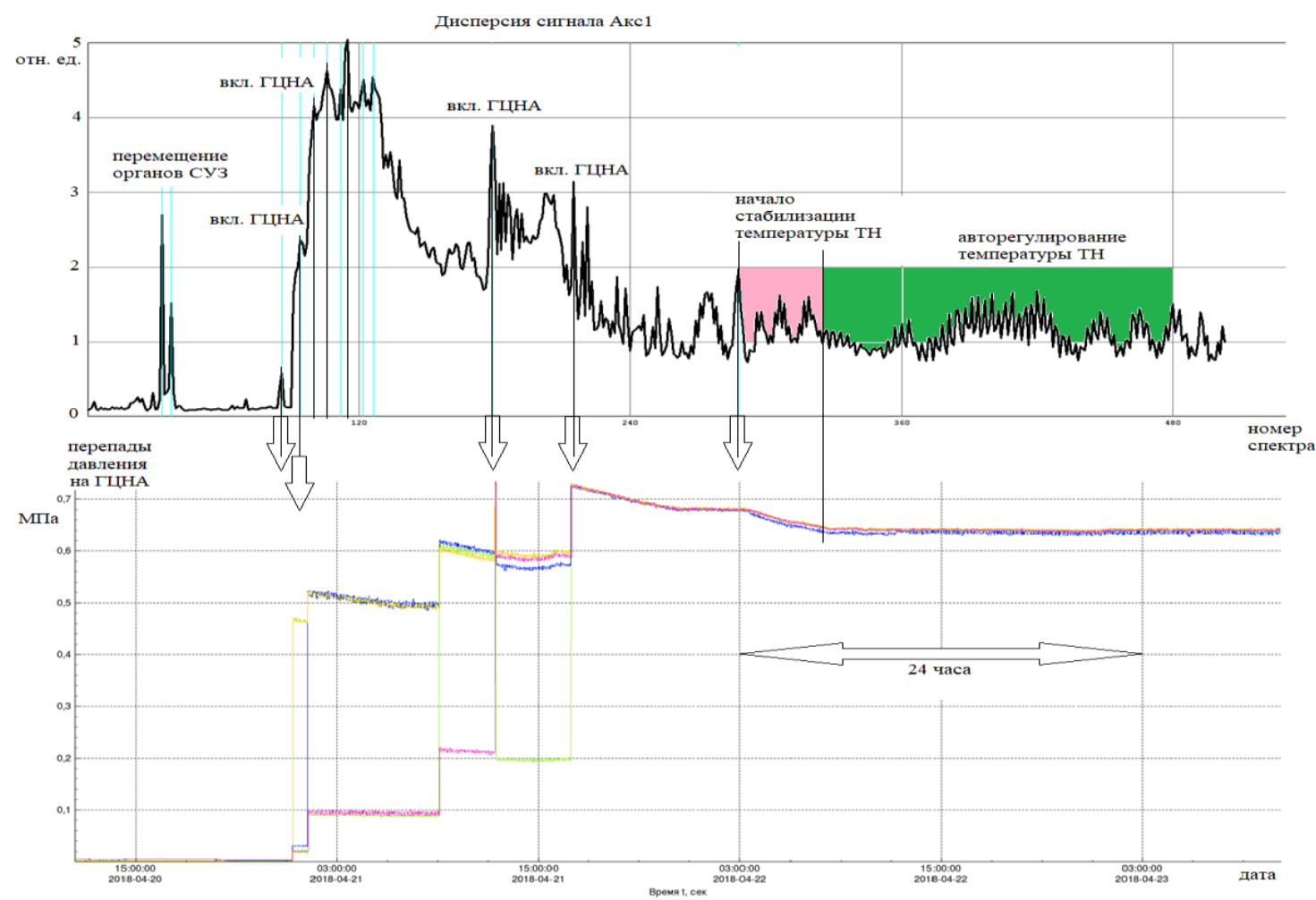

Рис. 4. Дисперсия сигнала корпусного акселерометра в течение разогрева блока РУ и перепады давления на ГЦНА (нижний график)

Очевидно влияние включения/отключения очередного ГЦНА на вибросостояние корпуса РУ при том, что его абсолютные виброперемещения ничтожно малы. Наблюдаются также скачки вибраций корпуса РУ при числе функционирующих ГЦНА менее 4-х из-за скачкообразных процессов переформирования поля АСВ. 


\section{Поле АСВ}

Экспериментально получены амплитудные распределения основных типов АСВ (рис. 5). Примечательно, что точки перегиба распределений, которые соответствуют максимуму градиента акустического поля, приходятся на горячий и холодный коллектора ПГ.

Акустические стоячие волны, как главный источник вибраций оборудования ВВЭР, представляются негативным явлением. Было бы заманчиво уменьшить их амплитуду за счёт управления механизмами поглощения энергии (в том числе и механизмом вязкости теплоносителя). Пусть для иллюстрации, одним механизмом поглощения будет трение ТН о стенки трубопровода, а другой механизм - сдвиговая вязкость в объёме теплоносителя. Механизм трения, очевидно, связан со скоростью продольной волны, а, значит, с её кинетической энергией. Механизм вязкости - с потенциальной энергией.

Если постоянные времени этих двух явлений совпадают $\left(\tau_{L}=\tau_{C}\right)$, то акустическое возмущение будет преодолевать среду трубопровода без фазовых искажений, то есть, не «растягиваясь» во времени, а только пропорционально уменьшаясь по амплитуде, не изменяя своей формы. На частотном языке это означает, что все спектральные компоненты продольной волны при прохождении среды трубопровода пропорционально уменьшили свои амплитуды исключительно из-за двух эффектов поглощения энергии, а не из-за эффектов отражения. В итоге, в трубопроводе с такими стенками, такой вязкой средой и такой нагрузкой не порождаются стоячие волны. Для ГЦК ВВЭР необходимы экспериментальные стендовые исследования, в которых будут подобраны механизмы согласованного поглощения энергии акустических волн.

Стоячая волна не будет возникать, если отражающая поверхность обладает абсолютными поглощающими свойствами. Таких поверхностей не так много в ГЦК:

- крышки коллекторов ПГ;

- поверхность ШВК, видимая со стороны холодных и горячих патрубков;

- наружная поверхность днища ШВК;

Поглощение акустической энергии особым материалом, покрывающим стенки элементов ГЦК, должно приводить к увеличению энтальпии теплоносителя, а, значит, к увеличению мощности РУ.

Если «холодные» патрубки корпуса РУ, в которых происходит поворот потока ТН, «сгладить» по внутренним поверхностям, то отражения уменьшатся. В «горячем» патрубке корпуса РУ, как в выходном элементе, работающим на трубопровод, необходима согласующая конструкция типа рупора, которая также уменьшит отражения.

Коррелирование сигналов ДПД разных петель позволило установить глобальность низших типов АСВ. На этих частотах наблюдаются синхронные (взаимосвязанные) колебания 4-х ГЦНА. Также в [1] показано, что ДПД, установленный вблизи «холодного» коллектора ПГ, чувствителен к медленным изменениям эксплуатационных характеристик ПГ (рис. 6), а ДПД, установленный вблизи «горячего» коллектора ПГ - к эксплуатационным характеристикам теплообменных трубок ПГ. Нелинейность зависимости частоты корпусной АСВ от температуры ТН при наборе мощности РУ является характеристикой паровой фазы ТН в активной зоне (рис. 8) 

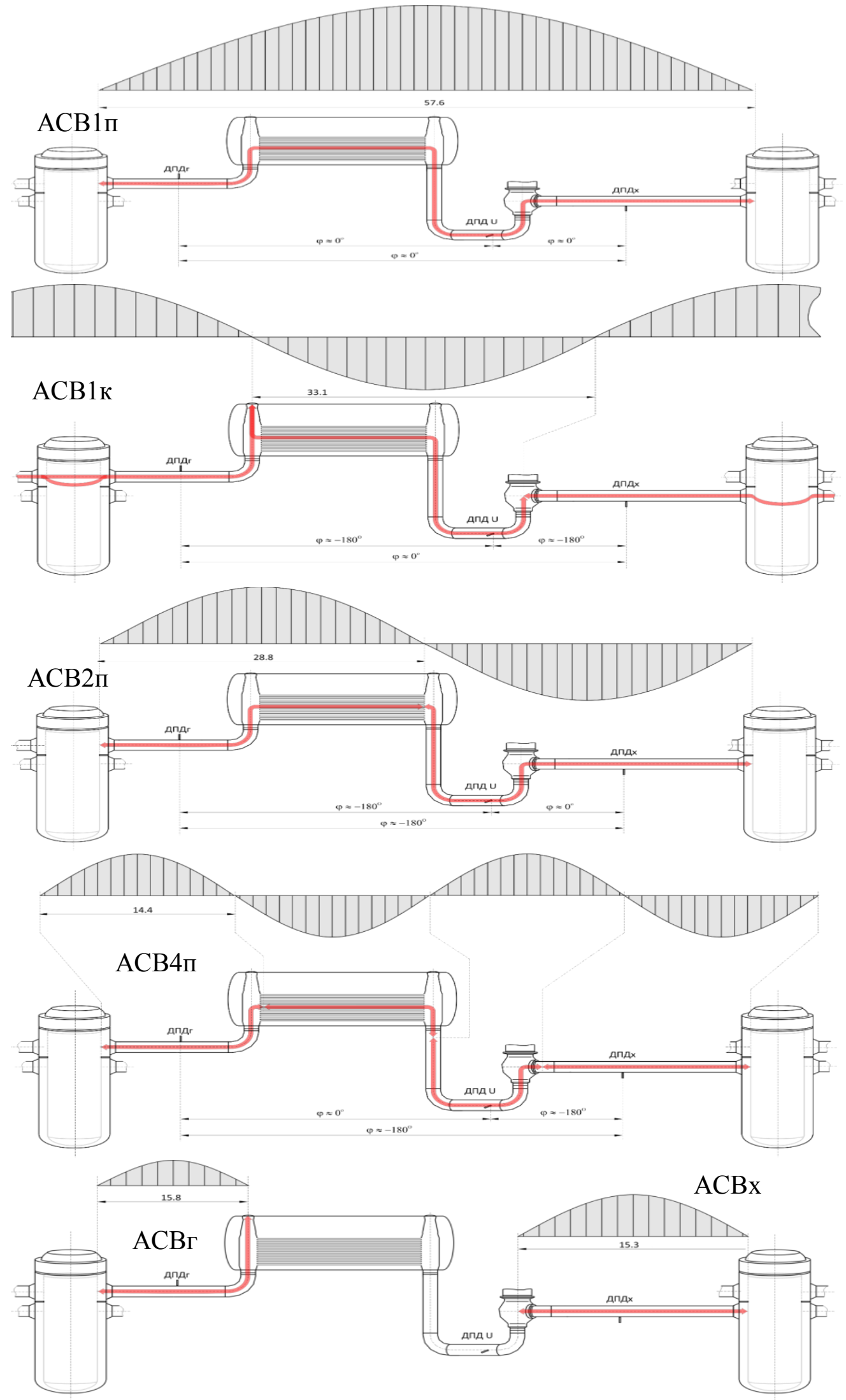

Рис.5. Амплитудные распределения основных типов АСВ 


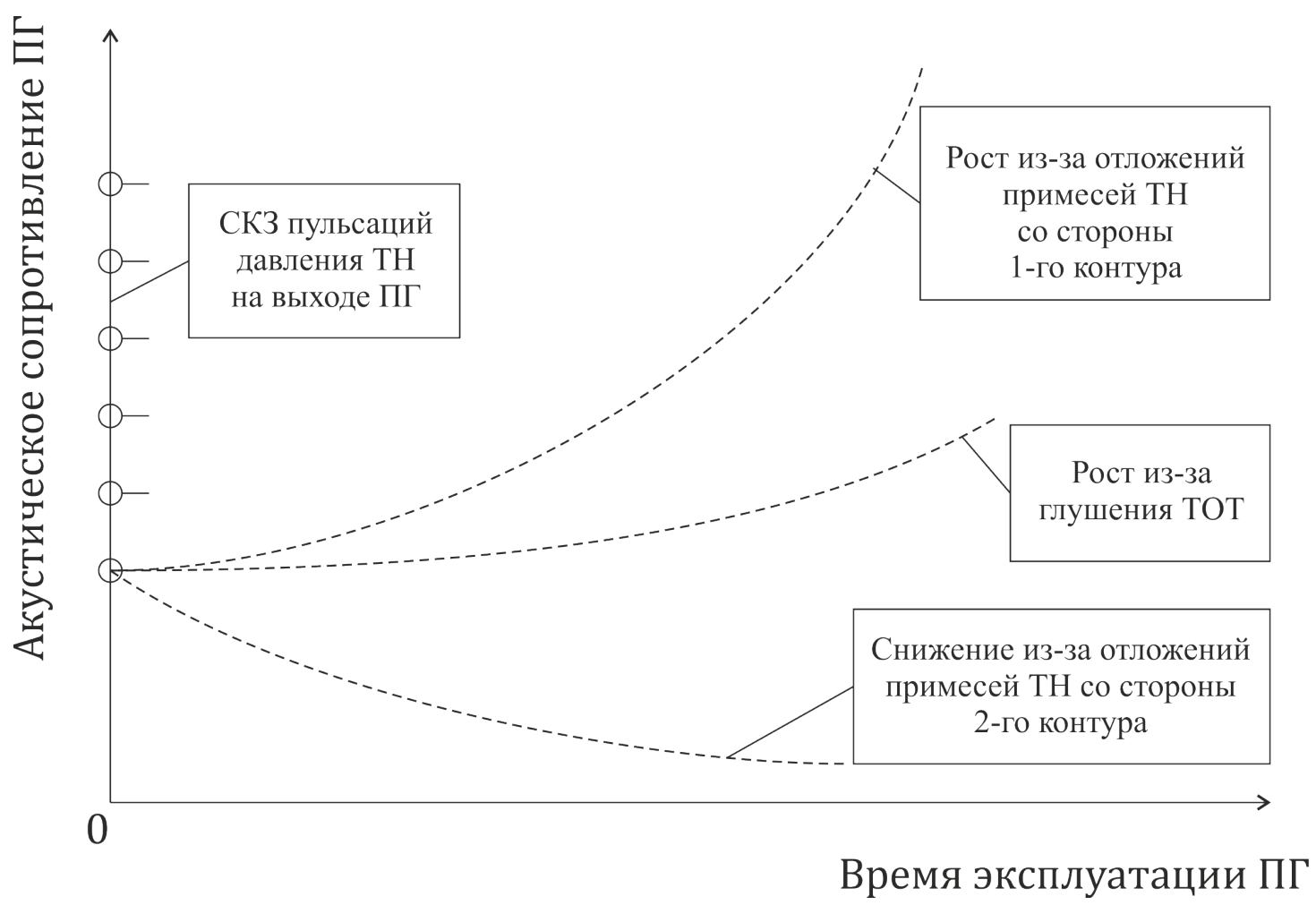

Рис. 6. Факторы изменения пульсаций давления ТН на выходе ПГ

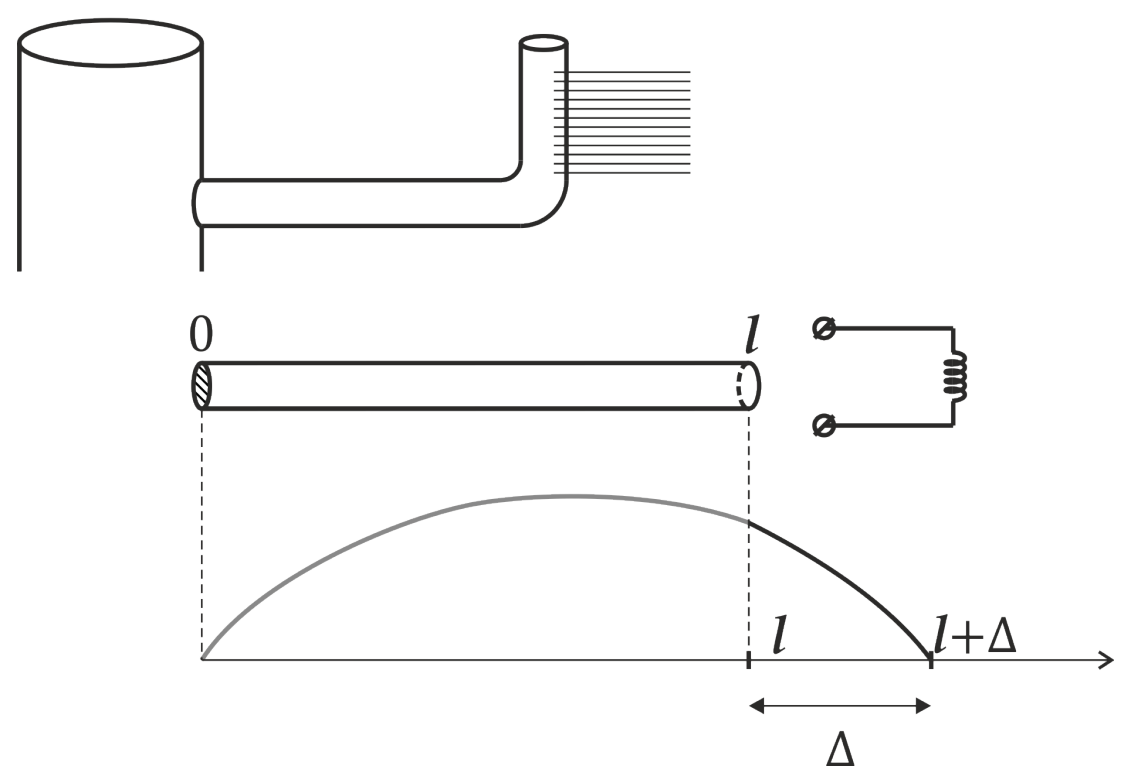

Рис. 7. Эффект увеличения длины волны при подсоединении индуктивной нагрузки (теплообменных трубок ПГ) 


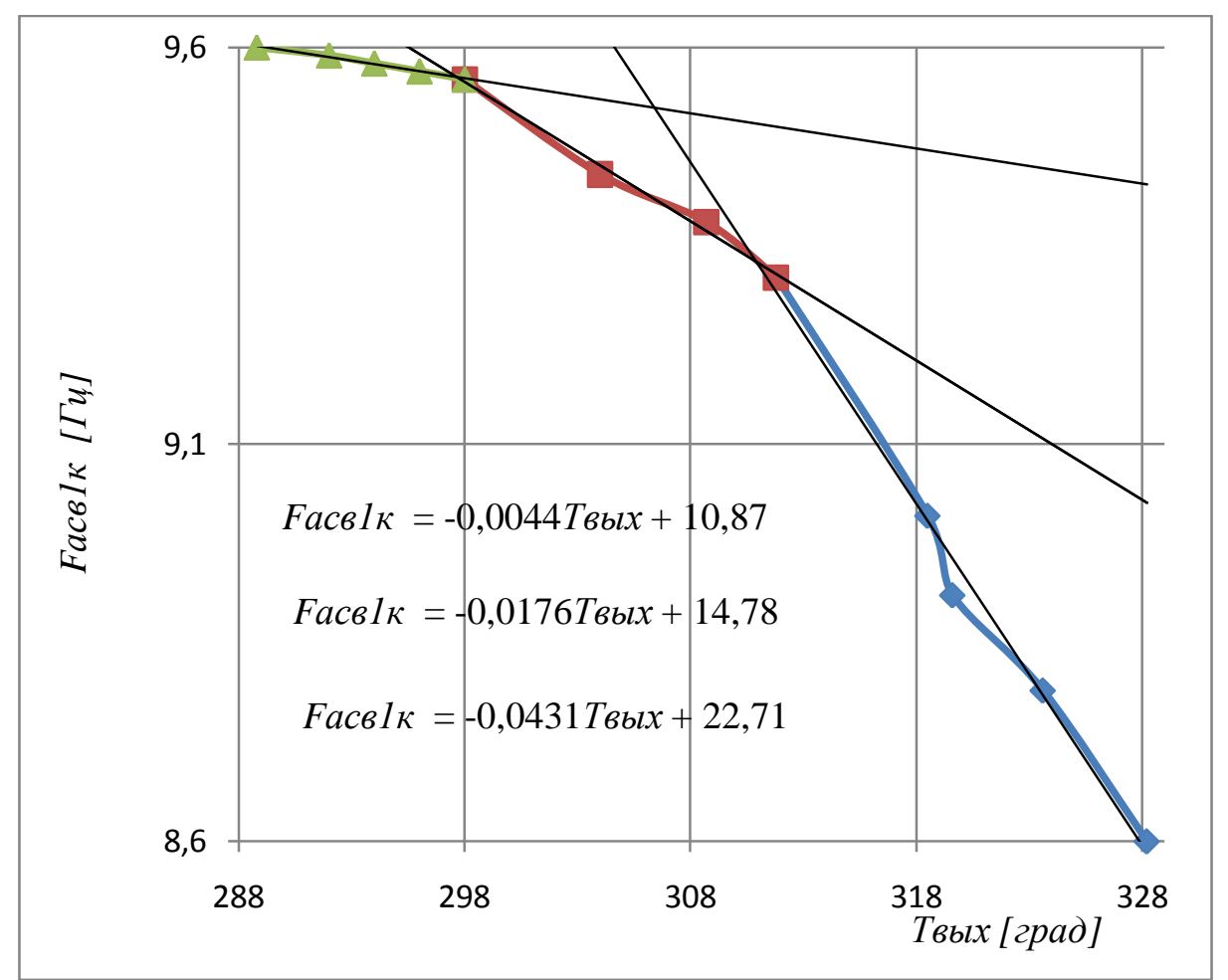

Рис. 8. Зависимость центральной частоты АСВ1к от температуры ТН на выходе Ак3, полученная по сигналу акселерометра, смонтированного на «холодном» трубопроводе ГЦК и

\section{Выводы} её три МНК-кусочно-линейных аппроксимаций.

Приведены теоретические и экспериментальные результаты по виброакустике ВВЭР1200 с приложениями к двум областям: проектирование и эксплуатация РУ. Особая роль придаётся этапу ПНИ. Поток виброакустической, диагностической информации, получаемый на ПГИ трудно переоценить. По ним необходимо составить стартовый виброакустический образ РУ и «обучить» стационарные системы диагностирования.

Применение виброакустики в реакторной инженерии идёт крайне медленно, возможно, из-за сложности математического аппарата, из-за наукоёмкости систем диагностирования, из-за отсутствия нормативных требований, регламентирующих акустические и вибрационные эффекты в ГЦК и требующие их непрерывного контроля. Значительные массогабаритные характеристики вибрирующих элементов конструкции, уникальная гидродинамика проточных частей и огромные величины вынуждающих вибрации сил выделяют вибрационный фактор в обосновании надёжности и ресурса оборудования РУ в специальную проблему.

\section{Литература}

1. Аркадов Г.В., Павелко В.И., Слепов М.Т. Виброакустика в приложениях к реакторной установке ВВЭР-1200: Наука, М.: 2018. 480 с. 